\title{
Cellulosic Ethanol: A Unique Sustainable Liquid Transportation Fuel
}

\author{
Charles E. Wyman (University of California-Riverside, USA)
}

\section{What Is Cellulosic Biomass?}

Although ethanol is now made from the sugars in the starch fraction of corn and other crops and from the sugar in sugarcane, a much greater impact for ethanol in terms of fuel use could be realized if the sugars from more recalcitrant cellulosic biomass could be converted to ethanol. Cellulosic biomass is the structural portion of plants and includes agricultural (e.g., corn stover, which is all of the above-ground portion of the corn plant, excluding the grain) and forestry (e.g., sawdust) residues, major fractions of municipal solid waste (e.g., waste paper and yard waste), and herbaceous (e.g., switchgrass) and woody (e.g., poplar) crops grown as energy resources. ${ }^{1}$ Although distinctive in outward appearance, these materials all comprise about $40-50 \%$ cellulose and $20-30 \%$ hemicellulose, with lesser amounts of lignin and other compounds such as sugars, oils, and minerals. Cellulose is a polymer of glucose sugar molecules that are physically linked together in a crystalline structure to provide structural support for plants. Hemicellulose is also made up of sugars covalently joined together in long chains, but it generally includes five different sugars: arabinose, galactose, glucose, mannose, and xylose. In addition, hemicellulose is an amorphous, branched material. Lignin is a phenylpropene compound that can be viewed as a low-sulfur, immature coal.

\section{Biological Conversion of Cellulosic Biomass to Ethanol}

The overall approach to converting cellulosic biomass to ethanol is outlined in Figure 1. Acids can break down the long chains in hemicellulose and cellulose to release the sugars comprising these materials through hydrolysis reactions, but because of their high specificity, enzymes known as cellulase can achieve higher yields of glucose from cellulose and are often favored. ${ }^{2}$ However, to survive in nature, cellulosic biomass has evolved a structure that resists enzymatic attack, and it must first be pretreated to better expose the cellulose to enzymes. Over the years, biological, chemical, mechanical, physical, and thermal pretreatments have been tried, but currently, only methods that treat biomass at temperatures of about $80-200^{\circ} \mathrm{C}$ with one or more chemicals have been able to realize the high sugar yields vital to economic success. Leading thermochemical pretreatment options include dilute sulfuric acid, ammonia fiber expansion (AFEX), neutral $\mathrm{pH}$, and lime, although the choice depends on many factors including the nature of the substrate, enzymes, and organisms and other process details. ${ }^{3,4}$

A portion of pretreated biomass can be used to feed a fungus or other organism that produces cellulase that can then be added to the bulk of the pretreated solids to release glucose from cellulose. In addition, the enzymes must be capable of releasing sugars contained in hemicellulose if the pretreatment step does not fully accomplish this. Then, an organism is added to ferment all of the sugars to ethanol. Although conventional yeasts ferment glucose and other sugars containing six carbon atoms efficiently, they do not use the five-carbon sugars arabinose and xylose well, and bacteria and yeasts have been genetically modified to accomplish this task. Following fermentation, the broth then passes into a distillation system for recovery and concentration of the ethanol, while the lignin and other portions not converted into ethanol can be burned to generate all of the heat and electricity needed to run the entire process, with excess power left to export to homes and businesses. The sugars released during pretreatment and/or enzymatic hydrolysis of hemicellulose and cellulose could also be biologically or chemically converted into other products in addition to ethanol, and lignin, an aromatic compound, could be employed to produce various materials such as adhesives and fillers. ${ }^{5}$

\section{Benefits of Cellulosic Ethanol}

Petroleum provides more energy internationally than any other source, accounting for about $35 \%$ of total energy produced, and unstable regions of the world hold the bulk of all known reserves. In addition, because over half of the petroleum is used for a transportation sector that is almost totally dependent on petroleum, developing alternative sources of liquid transportation fuels is vital to alleviating this perilous dependence, ${ }^{6}$ with biomass uniquely suited to sustainably meet this need. As one measure of its abundance, the U.S. Department of Agriculture (USDA) and Department of Energy (DOE) recently projected that about 1.3 billion dry tons of cellulosic biomass could be produced annually in the United States, from which enough ethanol could potentially be made to replace over half of the gasoline now used in the country.?

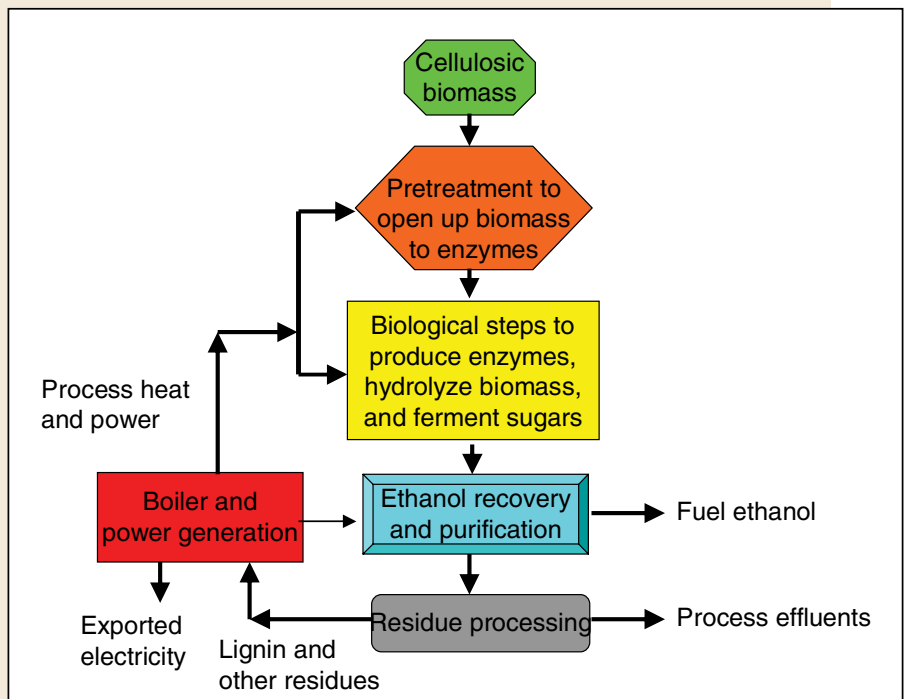

Figure 1. Overall process flow diagram illustrating the important operations in the biological conversion of cellulosic biomass to ethanol. 
Thus, cellulosic ethanol production could play a major role in significantly reducing petroleum imports, improving energy security, creating rural agricultural and manufacturing jobs, and dramatically cutting the trade deficit for oil imports.

Ethanol has higher octane content than regular or even premium gasoline; this property, coupled with a higher heat of vaporization, permits operation with a higher compression ratio when ethanol is used as a pure fuel. The result can be considerably better efficiency compared to gasoline in terms of miles powered per unit energy content of the fuel, compensating to some degree for the somewhat lower energy content of ethanol compared to gasoline. Thus, ethanol must sell for about $67-80 \%$ of the price of gasoline to provide equivalent cost per distance traveled. However, a larger portion of ethanol is used as blends with gasoline, and all automobile manufacturers warrant their vehicles for this use and employ appropriate materials in fuel lines to accommodate the somewhat greater corrosivity of blended ethanol. Although pure ethanol has low evaporative losses that can cause smog, lowlevel blends with gasoline increase evaporation somewhat, potentially negating some of the benefits for reducing tailpipe emissions.

In addition to the powerful strategic and economic attributes of cellulosic ethanol, the use of lignin to power the cellulosic ethanol production facility and the low fossil fuel inputs required to plant, grow, harvest, and transport cellulosic biomass and to transport ethanol to its destination result in very favorable energy balances for cellulosic ethanol. As a result, less than $10 \%$ of the ethanol energy produced has required fossil energy inputs. ${ }^{8}$ Even more importantly, these low fossil fuel requirements translate into very low net greenhouse gas emissions of less than $12 \%$ of those of gasoline; ${ }^{8}$ this ratio could be improved if the electricity exported to the power grid displaced requirements for coal and more renewable fuels were employed in all operations. ${ }^{9}$ In addition, more carbon dioxide could be removed than released in the process if the virtually pure carbon dioxide produced during fermentation could be sequestered in underground caverns or through other techniques being developed. ${ }^{10}$

\section{Technical and Economic Progress}

Cellulosic biomass is a low-cost feedstock, with a cost of about $\$ 40 /$ dry ton being competitive with petroleum at about $\$ 13 /$ barrel on an equivalent-energy-content basis. ${ }^{11}$ Although the resistance of biomass to biological breakdown has been historically expensive to overcome, an important advantage to using biological processes for this operation is that we can employ the power of modern biotechnology to dramatically improve the process and reduce processing costs. ${ }^{12}$ In this vein, advances in pretreatment, enzymes, and fermentative organisms as well as process integration have lowered the costs from about $\$ 4-5 /$ gal of ethanol in the early 1980 s to being competitive with ethanol made from corn now. ${ }^{13}$ Furthermore, costs as low as about $\$ 0.60 /$ gal could be realized if leap-forward technology advances were made in the most expensive processing steps: pretreatment and the biological conversion steps of enzyme production, enzymatic hydrolysis, and fermentation. ${ }^{14,15}$ For example, genetically modifying organisms to make their own enzymes while also fermenting the sugars they release to ethanol with high yields is one promising approach. Another would be advanced pretreatment systems, or plants that are genetically modified to be more susceptible so that just water could be used for pretreatment, thus avoiding the need for exotic materials of construction. Advances in low-cost materi- als of construction to handle dilute acid or other chemicals would also be invaluable.

\section{Commercial Challenges}

Despite its tremendous potential benefits and ongoing technical and economic progress, cellulosic ethanol technology has yet to be commercialized. First, enzymes have been too expensive historically, but through funding from the U.S. DOE, both Novozymes and Genencor claim to now be able to produce low-cost enzymes. ${ }^{16,17}$ In addition, although operating costs can be low for technology that achieves high ethanol yields, capital costs are high, and private investors are reluctant to undertake such large projects for first-of-a-kind operations. The fact that ethanol is a commodity product with tight margins further impedes commercialization. Thus, the inherently high capital costs coupled with the high cost of capital for first projects is the major obstacle. ${ }^{15}$ Various opportunities can be employed to counter this risk, such as retrofitting existing facilities, financing with low-cost government bonds, selling higher value coproducts, and using low-cost wastes as feedstocks. However, although cellulosic ethanol can ultimately compete without subsidies, government assistance and policy will likely be critical to overcoming the concerns about risk for first applications and getting the industry off the ground, just as it was in facilitating the emergence of the petrochemical industry during World War II. To be effective, incentives for the first few commercial facilities must be permanent so that large capital investments cannot be stranded by changes in government policy. Improving our knowledge of the fundamentals of the complex interaction of solid cellulosic biomass with enzymes and organisms would also build confidence in technology applications and suggest routes for dramatically advancing the technology to reduce costs.

\section{Closing Thoughts}

The production of ethanol from low-cost and abundant cellulosic biomass provides a powerful and unique route to sustainable production of liquid transportation fuels that our society uses so extensively and offers tremendous economic, strategic, and environmental benefits. Significant progress has been made in advancing the technology so that it is costcompetitive now, and lower costs are foreseeable. However, the challenge to widespread use and commercialization is overcoming the risk of first applications, with well-directed government policies likely being critical to the emergence of this industry, an industry that can have a major impact on our quest to reduce use of petroleum from unstable regions of the world and also cut greenhouse gas emissions that present a mounting threat to our way of life.

\section{Acknowledgments}

The author is grateful to the Ford Motor Company for sponsoring the Chair in Environmental Engineering at the Bourns College of Engineering at the University of California, Riverside, and for providing funds for our research on cellulosic ethanol.

\section{References}

1. C.E. Wyman, S.R. Decker, M.E. Himmel, J.W. Brady, C.E. Skopec, L. Viikari, in Polysaccharides: Structural Diversity and Functional Versatility, S. Dumitriu, Ed. (Dekker, New York, ed. 2, 2004), p. 995.

2. C.E. Wyman, in Encyclopedia of Energy, C. Cleveland, Ed. (Elsevier, St. Louis, M0, 2004), p. 541

3. C.E. Wyman, B.E. Dale, R.T. Elander, M. Holtzapple, M.R. Ladisch, Y.Y. Lee, Bioresour. Technol. 96 (18), 2026 (2005). 
4. N. Mosier, C.E. Wyman, B. Dale, R. Elander, Y.Y. Lee, M. Holtzapple, M. Ladisch, Bioresour. Technol. 96 (6), 673 (2005).

5. C.E. Wyman, Applied Energy Technology Series, 424 (Taylor and Francis, Washington, DC, 1996)

6. U.S. Department of Energy, Energy Information Administration, Annual Energy Review 2005 (DOE Report DOE/EIA-0384, 2005).

7. R. Perlack, L. Wright, A. Turhollow, R. Graham, B. Stokes, D. Erbach,

Biomass as Feedstock for a Bioenergy and Bioproducts Industry: The

Technical Feasibility of a Billion-Ton Annual Supply (Oak Ridge National Laboratory, Oak Ridge, TN, 2005).

8. A.E. Farrell, R.J. Plevin, B.T. Turner, A.D. Jones, M. O'Hare, D.M. Kammen, Science 311, 506 (2006).

9. C.E. Wyman, Appl. Biochem. Biotechnol. 45-6, 897 (1994).
10. H.S. Kheshgi, R.C. Prince, Energy 30, 1865 (2005).

11. L.R. Lynd, C.E. Wyman, T.U. Gerngross, Biotechnol. Prog. 15 (5), 777 (1999).

12. U.S. Department of Energy, Office of Science, Breaking the Biological Barriers to Cellulosic Ethanol, a Joint Research Agenda, a Research Roadmap Resulting from Biomass-to-Biofuels Workshop, Rockville, December 2005 (DOE/SC 0095, June 2006).

13. C.E. Wyman, Annu. Rev. Energy Environ. 24, 189 (1999).

14. L.R. Lynd, R.T. Elander, C.E. Wyman, Appl. Biochem. Biotechnol. 57-58, 741 (1996).

15. C.E. Wyman, Trends Biotechnol. 25 (4), 153 (2007).

16. Chem. Eng. Prog. 100 (12), 15 (2004).

17. Chem. Eng. News 83 (17), 10 (April 25, 2005).

\title{
Engineered and Artificial Photosynthesis: Human Ingenuity Enters the Game
}

\author{
Devens Gust (Arizona State University, USA), David Kramer (Washington State University, USA), \\ Ana Moore (Arizona State University, USA), Thomas A. Moore (Arizona State University, USA), \\ and Wim Vermaas (Arizona State University, USA)
}

All oxygen-dependent life depends on photosynthesis. In addition to breathing the oxygen produced by photosynthesis, humans have been harnessing energy from photosynthesis for millennia. Since the beginning of human societal structures, human needs have driven the evolution of agricultural production, and they continue to do so. Recently, it has been suggested that agriculture can contribute substantially to human technological (nonnutritional) energy needs. This possibility raises concern because the projections of human energy needs argue convincingly that without large increases in energy conversion efficiency (ECE), land-grown biofuel production and food production will compete for land, a largely untenable compromise given the current nutritional status of the world's underdeveloped societies.

In addition to using the fuel provided by nature's photosynthetic process, humans have devised direct routes for harnessing solar energy including, for example, photovoltaic (PV) cells. These cells produce energy in the form of electromotive force (emf, electricity), which, although ideal for many applications, is not easily stored and used for fuel (e.g., in transportation). We posit that transformational progress toward meeting the goals of supplanting fossil fuels, providing energy security, and mitigating climate change can be made at the intersection of technology and biology. This intersection comprises artificial photosynthesis, other bio-inspired energy conversion processes, and the design of organisms that specialize in efficient biofuel production from solar energy. As outlined here, artificial constructs can contribute directly to solar energy conversion, can be incorporated into hybrid systems, and can inform the design of new photosynthetic organisms.

\section{What Do We Mean by Efficient, and Why Isn't Natural Photosynthesis More Efficient?}

The initial energy-conserving steps in the conversion of solar energy to either electricity or biomass can be described by elementary photophysical processes; the essential ones are shown in Figure 1. The absorption of light (red and green arrows) promotes an electron to a higher energy level, which leads to an excited state in which an electron is repositioned in spatial and energy coordinates and a positive charge (hole) is left behind. This is the transformation of solar to chemical energy; the electron is chemically reducing (low electrochemical potential), and the hole is chemically oxidizing (high electrochemical potential). In molecular systems, the further stabilization necessary to prevent wasteful relaxation back to the ground state involves moving the electron and hole farther apart; there is a concomitant loss of energy (illustrated by the dash-dotted arrows in Figure 1) necessary to drive this charge separation process. In typical PV cells, the hole and electron are separated and thereby stabilized by an internal electric field at the junction of the $n$ - and $p$-type semiconductor materials. The energy associated with separating the charges (dash-dotted arrows in Figure 1) reduces the electrical energy available in the external circuit. Charge separation sets the stage for describing three efficiency-defining processes: a high fraction of the photons absorbed must yield charge separation (i.e., the quantum yield of charge separation must be high); the energy of the charge-separated state must be high; and recombination of the electron and hole, producing heat, must be much slower than chemical reactions making productive use of the oxidation and reduction potential (or slower than the conduction of charge in a PV device).

ECE is defined as the usable electrical or harvestable chemical energy output divided by the total solar energy incident on the organism or device. In terms of meeting human energy needs, which are usually expressed on an annual basis, it is convenient to calculate ECE using insolation (incident solar energy) per year summed over diurnal and seasonal cycles. ECE is a fundamental parameter that determines the area required to provide a specified amount of energy for human use. Some examples of the ECEs of 